\title{
Policy-Induced Market Distortions along Agricultural Value Chains: Evidence from Ethiopia and Nigeria
}

\section{Summer Allen, Girma Kassie, Fahd Majeed, and Simla Tokgoz}

I he functioning and performance of agrifood value chains are particularly important for the livelihoods of smallholder farmers in developing countries.

Development of agrifood value chains is a critical component of rural transformation, opening new markets for farmers and supplying food products to urban areas and for export. Agricultural policies have repercussions not only at the farm-level, but also along the entire value chain of a commodity, affecting various value chain actors in different ways as well as the performance of the value chain. Measuring and understanding how policies impact particular value chains is necessary to design effective policies that minimize unintended consequences for value chain actors.

Policy-induced market distortions are the result of policies such as taxes, subsidies, minimum support prices, and government procurement that alter domestic prices along the value chain. This brief summarizes an analysis of these distortions in value chains in two developing countries: Ethiopia and Nigeria. To determine how agricultural policies are affecting value chains, we looked at nominal rates of protection (NRPs), a measure of how these policies affect prices for producers and consumers (Box 1). We apply the NRP methodology developed by Krueger, Schiff, and Valdes (1988) to agricultural value chains in Ethiopia and Nigeria.

\section{KEY POLICY FINDINGS}

- Agricultural policies at state, regional, and national levels have repercussions well beyond the farm. These policies influence prices and market conditions along the entire agrifood value chain of a commodity.

- Policymakers can identify how agricultural policies influence prices faced by consumers, producers, traders, and processors using a standard methodology to measure agricultural (dis)incentives - the nominal rate of protection.

- High costs of market access for actors along agrifood value chains, found in case studies in Ethiopia and Nigeria, reflect weak integration of these value chains and generate welfare losses for both producers and consumers. Measures that focus on lowering the cost of market access by easing access to inputs, improving infrastructure, and strengthening supply chain linkages would benefit both producers and consumers.

Our results show that agricultural policies have significant impacts on prices beyond the farm, extending along entire value chains for agrifood products. Agricultural policies shape incentives for all actors along the value chain, with

\section{NOMINAL RATE OF PROTECTION: A BRIEF EXPLANATION}

Nominal rate of protection (NRP) is a measure of policy-induced market distortions in product prices; it allows for comparison of taxation or subsidization rates across different products and across different points in a value chain.

The NRP methodology, developed by Krueger, Schiff, and Valdes (1988), calculates the gap between the domestic price of a commodity and the reference price (that is, the price that would prevail under perfect market conditions and in the absence of policy impacts) at the same point in the value chain. Dividing this difference by the reference price provides the distortionary impact, or NRP, as a percentage.

Positive NRPs indicate that producers receive prices above prevailing international prices, meaning that policies have subsidized the producers. Negative NRPs indicate that producers receive prices below international prices, meaning policies have taxed the producers. 
impacts on value chain integration and development and, more broadly, rural development. Agricultural policymakers must have a measure of these impacts if they wish to balance the needs and interests of farmers, traders, processors, retailers, and consumers alike, and promote the development of efficient value chains.

\section{POLICY FINDINGS}

\section{Local and state policies matter.}

In the value chains under analysis, NRPs at the farmgate were found to vary across regions within both Nigeria and Ethiopia. Regional and state-level policy frameworks explain some of the variations in prices that producers receive. Local conditions that impact price transmission - such as variations in transaction costs, quality premiums, or mark-ups captured by traders - can also contribute to regional heterogeneity in farmgate NRPs. For example, within Nigeria, farmgate NRPs for palm oil and cocoa value chains differ substantially across regions (Figure 1 and Figure 2), indicating that regional and state policies also affect farmers. They also show that farmers in different localities may be affected differently by the national policy framework due to local price transmission issues. Thus, to best aid all farmers, policymakers should consider how different regions may be affected when setting the policy agenda.

\section{FIGURE 1 Regional farmgate NRPs for palm oil in Nigeria}

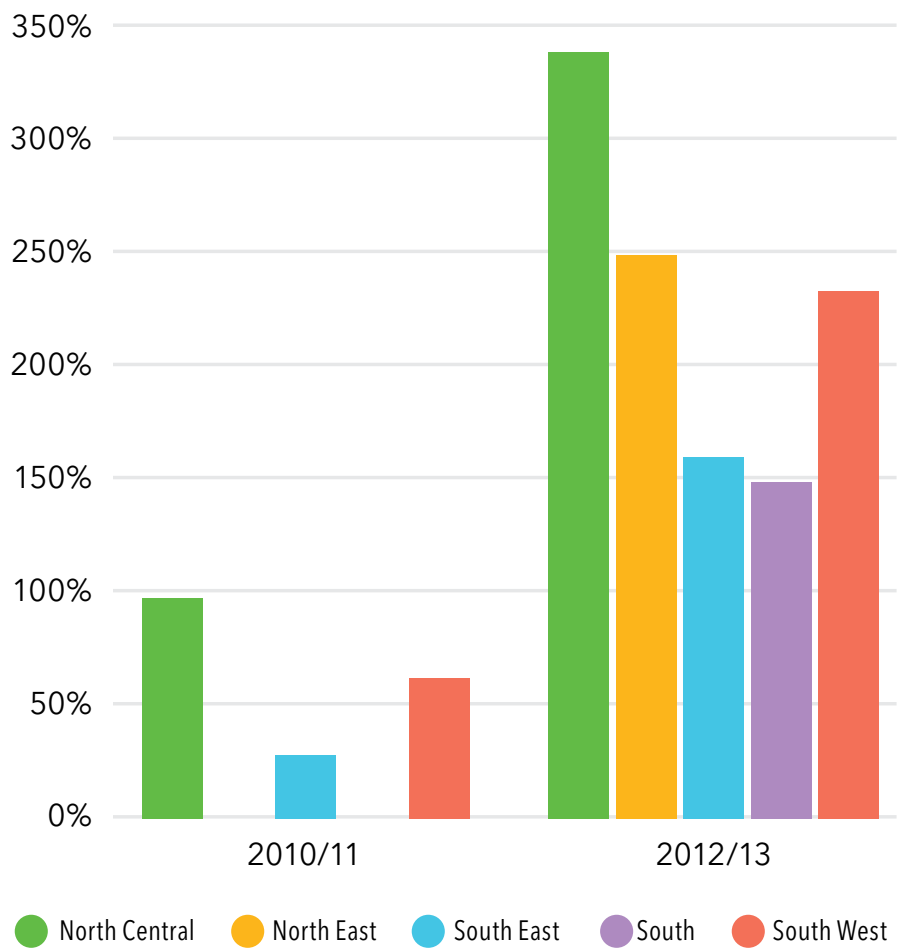

Source: Tokgoz et al. (2020).
FIGURE 2 Regional farmgate NRPs for cacao beans in Nigeria

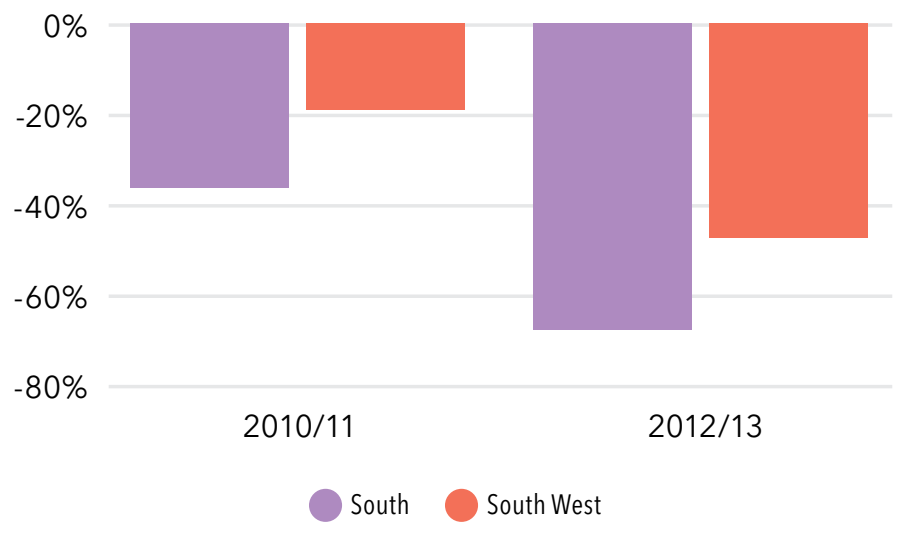

Source: Tokgoz et al. (2020).

To improve value chains, policymakers should both reevaluate the existing policy framework and focus on inefficiencies along the value chain.

Both policies and market access costs, such as processing, transportation, distribution, storage, and other costs (brokerage fees and market access fees), contribute to the difference between producer and consumer prices (Box 2). Efforts to improve the functioning of value chains must address problems with both policies and market access.

The studies in Ethiopia and Nigeria show that market access costs along the value chains of these two developing countries are high. These high access costs reflect inefficiencies in moving commodities from producers to consumers along the nodes of the value chain, for example, high transportation costs due to poor infrastructure and high fees due to the market power of traders, which increase the difference between consumer and producer prices. For example, we computed the access costs for Ethiopia's small ruminant (sheep and goats) markets throughout the nodes of the value chains based on household survey data, and found them to be positive and high in value.

Policy-induced distortions, such as those caused by taxes, subsidies, and minimum support prices, were separated from market inefficiencies using data on access costs. For Ethiopia's small ruminant markets, policy-induced market distortions to prices along the value chains are also quite high (Figure 4 and Figure 5). We computed the NRPs at different points along the value chains, finding that the NRPs at the farmgate and the retail market for both sheep and goats are negative across time. NRP values were strongly negative, indicating a large deviation of both producer and retailer prices from the comparable export prices. This implies that government policies are taxing value chain participants rather than protecting them. 
The NRP methodology compares domestic prices with a reference price - that is, an undistorted price that excludes the impact of policies and market access costs. It relies on the law of one price when comparing the domestic and the reference prices, meaning these prices must refer to goods that are comparable (in terms of quality, processing level, and location). Reference prices are computed using international prices. To make these prices comparable with domestic prices, they are adjusted using quality and quantity conversion factors, such as converting the paddy rice price to the milled rice price, and by adding/subtracting market access costs along the nodes of the value chain. Figure 3 illustrates these nodes and associated costs. Thus, the final difference between the domestic and the reference prices, and likewise the final NRP, measures only the impact of the policy on prices, excluding other factors that may contribute to a price gap.

\section{FIGURE 3 Price transmission across different locations of measurement}

\section{Border Price}

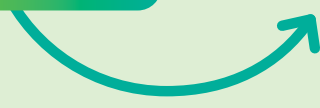

\section{Reference Price}

- Official Exchange Rate

- Quantity Adjustment

- Quality Adjustment

Source: Authors' description.

FIGURE 4 NRPs at point of competition and farmgate for sheep at national level in Ethiopia

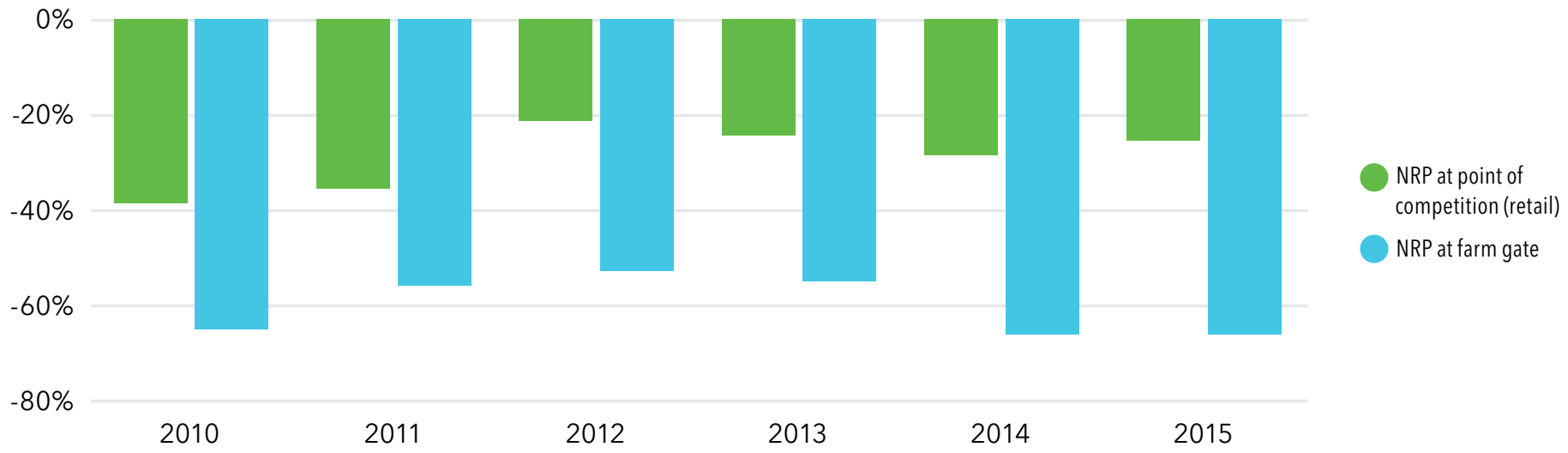

Source: Kassie et al. (2019).

\section{FIGURE 5 NRPs at point of competition and farmgate for goats at national level in Ethiopia}

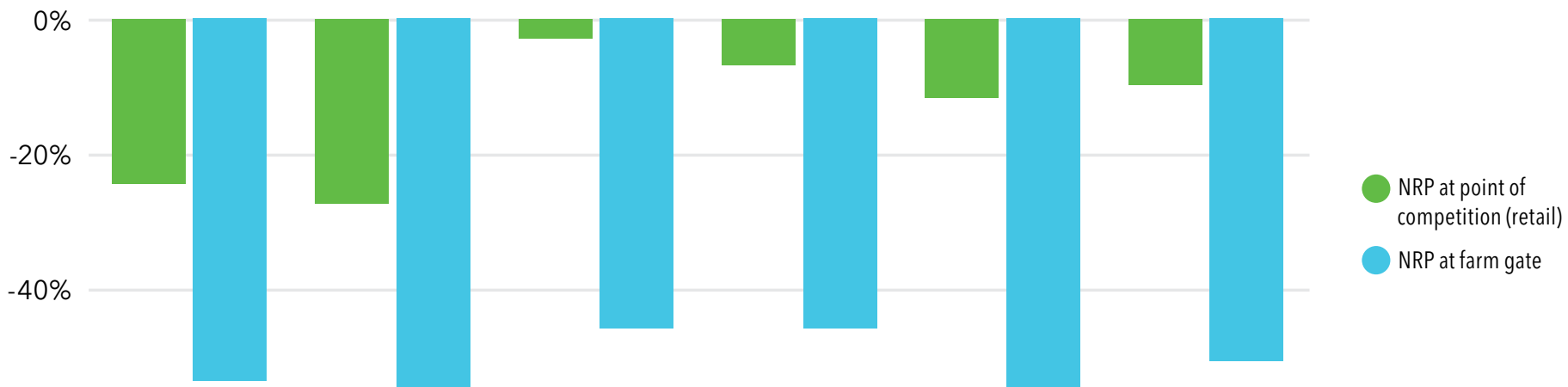


Trade policies and domestic agricultural policies have overlapping outcomes.

In addition to the differences noted in the impacts of domestic agricultural policies along the value chain, trade policies also affect value chains. Analysis of Nigerian value chains focused on palm oil (of which Nigeria is a net importer) and cacao (of which Nigeria is a net exporter). Palm oil producers have been subsidized and protected from global price fluctuations by trade policies and domestic initiatives. Both border and farmgate NRPs are positive for palm oil (Figure 6). The protective trade policy increases the price of palm oil coming into Nigeria, which helps local producers by increasing the domestic price. However, consumers are hurt since they are paying more for palm oil.
In Nigeria's export-oriented cocoa value chain, NRPs at the border for cacao beans and cocoa products are negative, meaning that exporters received prices below world market prices (Figure 7). This may reflect the quality gap, the export market structure, and/or the concentration of buyers in global markets. NRPs are also negative at the farmgate for cacao beans in all regions of the country, despite domestic support policies, such as distribution of improved cacao varieties and agricultural inputs to aid cacao bean farmers. This illustrates how disincentives in the cacao bean export market echo through the domestic market. Effectively taxing exports for revenue purposes lowers prices received by farmers, thus reducing domestic supply and hampering value chain development.

\section{FIGURE 6 Palm oil NRPs at the border and the farmgate, and import tariffs in Nigeria}

$250 \%$

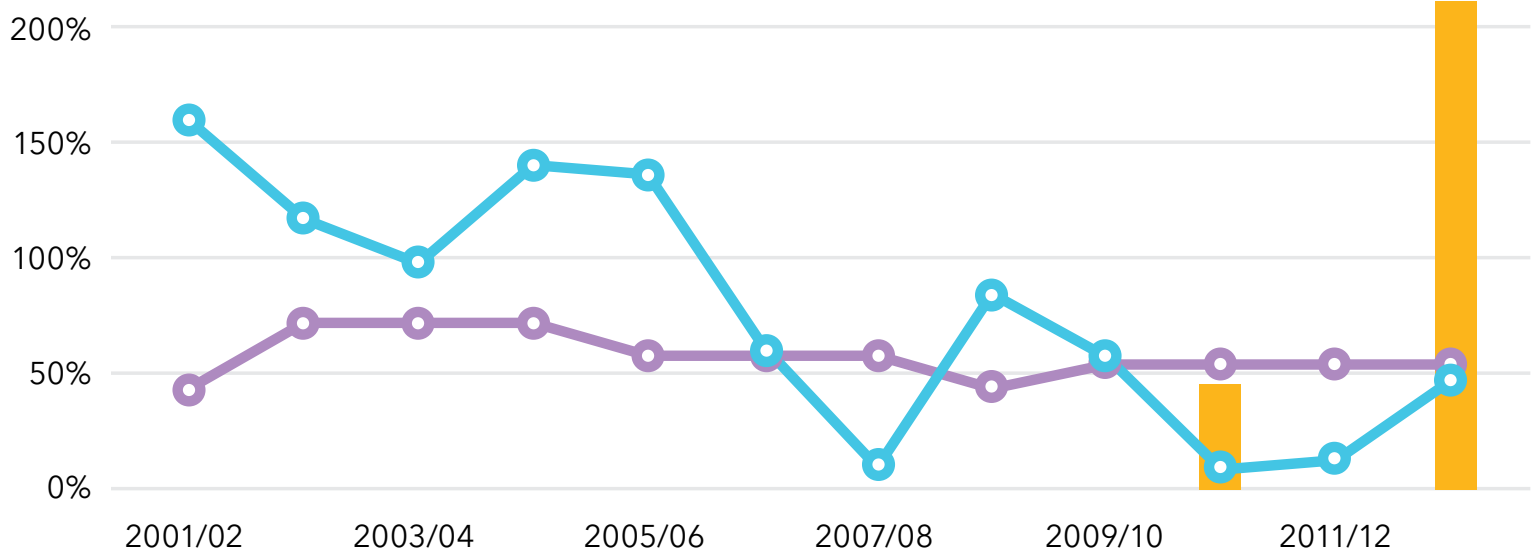

Source: Tokgoz et al. (2020).

\section{FIGURE 7 Cocoa value chain NRPs at the border in Nigeria}

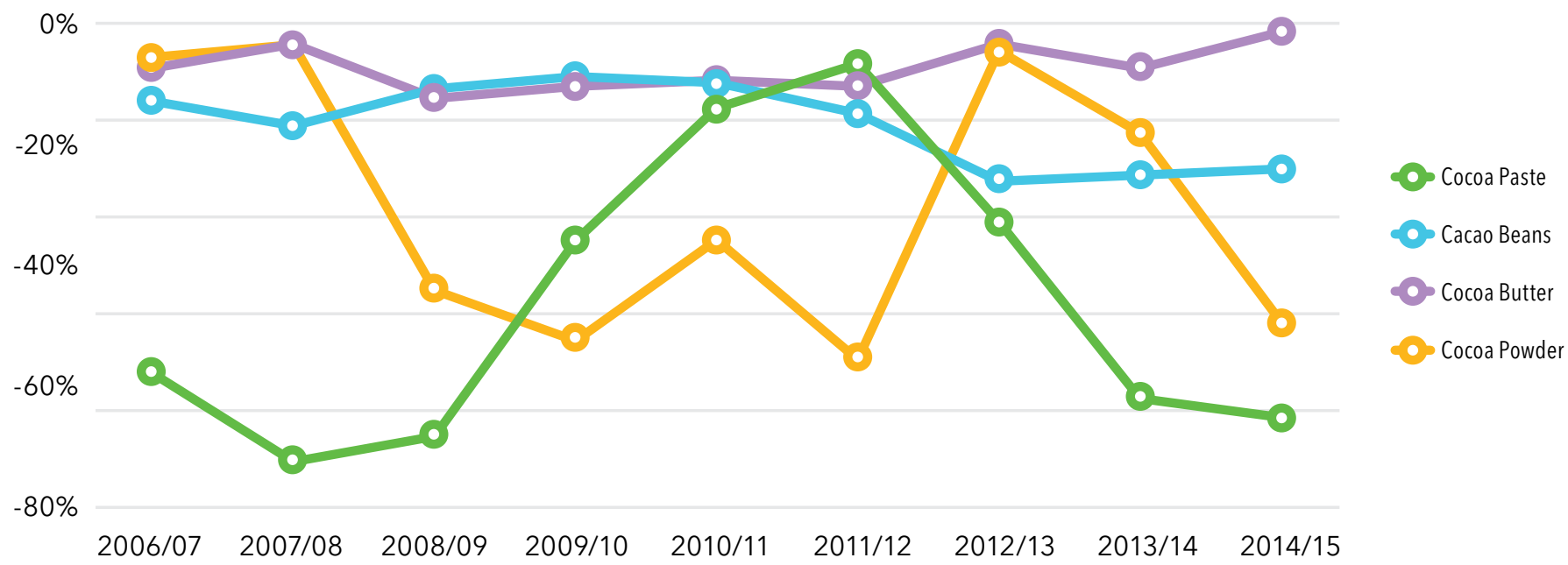

Source: Tokgoz et al. (2020). 


\section{LESSONS LEARNED}

To achieve food and nutrition security, developing countries implement a wide range of agricultural, trade, and domestic policies. Poorly informed policies can be harmful to different actors across agrifood value chains. Using the NRP methodology to analyze incentives along value chains would allow policymakers to create a coherent policy framework and understand the full implications of their policies. Policies that improve access to inputs and markets, including through improved infrastructure, will foster better integration of domestic value chains and expand markets for all farmers and processors. They should also allow value chain operators to connect better to and enhance gains from participation in global agrifood value chains. Governments should review their agricultural marketing policies and, as appropriate, change these to improve farmers' access to markets and allow farmers to garner a greater share of total value added in agrifood commodity supply chains. This is especially critical in developing countries that export unprocessed agricultural goods, such as cacao beans in Nigeria. Most critically, policymakers should provide a policy framework for domestic value chain development that is consistent in its objectives.

\section{References}

Kassie, G.T., R.S. Wube, S. Tokgoz, F. Majeed, M. Yitayih, and B. Rischkowsky. 2019 "Policy-Induced Price Distortions along the Small Ruminant Value Chains in Ethiopia." Journal of Agribusiness in Developing and Emerging Economies 9 (3): 220-236.

Krueger, A.O., M. Schiff, and A. Valdes. 1988. "Agricultural Incentives in Developing Countries: Measuring the Effect of Sectoral and Economywide Policies." World Bank Economic Review 2 (3): 255-271.
Tokgoz, S., S. Allen, F. Majeed, B. Paris, O. Adeola, and E. Osabuohien. 2020 "Distortions to Agricultural Incentives: Evidence from Nigerian Value Chains." Review of Development Economics, preprint April 24

World Bank. 2020. World Development Report 2020: Trading for Development in the Age of Global Value Chains. Washington, DC: World Bank.

Summer Allen is a senior research associate at JBS International. Girma Kassie is a senior agricultural market economist with the Social, Economics and Policy research team, International Center for Agricultural Research in the Dry Areas (ICARDA). Fahd Majeed is a graduate student in the Department of Agriculture and Consumer Economics at the University of Illinois at Urbana-Champaign. Simla Tokgoz is a research fellow in the Markets, Trade, and Institutions Division, International Food Policy Research Institute.

This work was undertaken as part of, and funded by, the CGIAR Research Program on Policies, Institutions, and Markets (PIM) led by the International Food Policy Research Institute (IFPRI). PIM is in turn supported by these donors (https://pim.cgiar.org/ about/funders/).

This is a peer-reviewed publication. Any opinions stated herein are those of the authors and are not necessarily representative of or endorsed by IFPRI, PIM, ICARDA, or CGIAR.

\section{INTERNATIONAL FOOD POLICY RESEARCH INSTITUTE}

\section{A world free of hunger and malnutrition}

IFPRI is a CGIAR Research Center 